\title{
Patient Position and Semi-Rigid Ureteroscopy Outcomes
}

\author{
Fernando Korkes, Antonio C. Lopes-Neto, Mario H. E. Mattos, Antonio C. L. Pompeo, Eric R. \\ Wroclawski
}

Division of Urology, ABC Medical School, Santo Andre, Sao Paulo, Brazil

\begin{abstract}
Introduction: Two positions have been reported for ureteroscopy (URS): dorsal lithotomy (DL) position and dorsal lithotomy position with same side leg slightly extended (DLEL). The aim of the present study was to compare the outcomes associated with URS performed with patients in DL vs. DLEL position.

Materials and Methods: A total of 98 patients treated for ureteral calculi were randomized to either DL or DLEL position during URS, and were prospectively followed. Patients, stone characteristics and operative outcomes were evaluated.

Results: Of the 98 patients included in the study, $56.1 \%$ were men and $43.9 \%$ women with a mean age of $42.6 \pm 16.8$ years. Forty-eight patients underwent URS in DL position and 50 in DLEL position. Patients' age, mean stone size and location were similar between both groups. Operative time was longer for the DL vs. DLEL group ( 81.0 vs. 62.0 minutes, $\mathrm{p}=0.045)$, mainly for men (95.2 vs. 63.9 minutes, $\mathrm{p}=0.023)$. Mean fluoroscopy use, complications and success rates were similar between both groups.

Conclusions: Most factors associated with operative outcomes during URS are inherent to patient's condition or devices available at each center, and therefore cannot be changed. However, leg position is a simple factor that can easily be changed, and directly affects operative time during URS. Even though success and complication rates are not related to position, placing the patient in dorsal lithotomy position with an extended leg seems to make the surgery easier and faster.
\end{abstract}

Key words: ureteroscopy; ureteral calculi; lithotripsy; prospective studies; lithiasis; urinary catheterization Int Braz J Urol. 2009; 35: 542-50

\section{INTRODUCTION}

Ureteroscopy (URS) has gained widespread use for the treatment of ureteral stones $(1,2)$. For most endoscopic procedures, patients are placed in the standard dorsal lithotomy position and the perineum flush with the end of the cystoscopy table. Two positions have been reported for URS procedures: dorsal lithotomy position with legs supported in stirrups with minimal flex at the hips (DL) $(3,4)$; and dorsal lithotomy position with one leg (same side of ureteral stone) slightly extended, and the hip abducted (DLEL) (5) (Figure-1). This position has the theoretical advantage of minimizing the angulation of the ureter, facilitating passage and advancement of the ureteroscope $(6,7)$.

However, different groups have adopted both positions, and after video cameras had been selected for such procedures, many surgeons have subsequently used the DL position. To our knowledge, no studies have assessed the differences between these two approaches. The aim of the present study was to compare the outcomes associated with URS performed with patients in DL vs. DLEL position, significant operative time, stone free and complication rates. As secondary outcomes, fluoroscopy time, need for ureteral dilatation, use of ureteral stents and length of hospital stay was also assessed. 

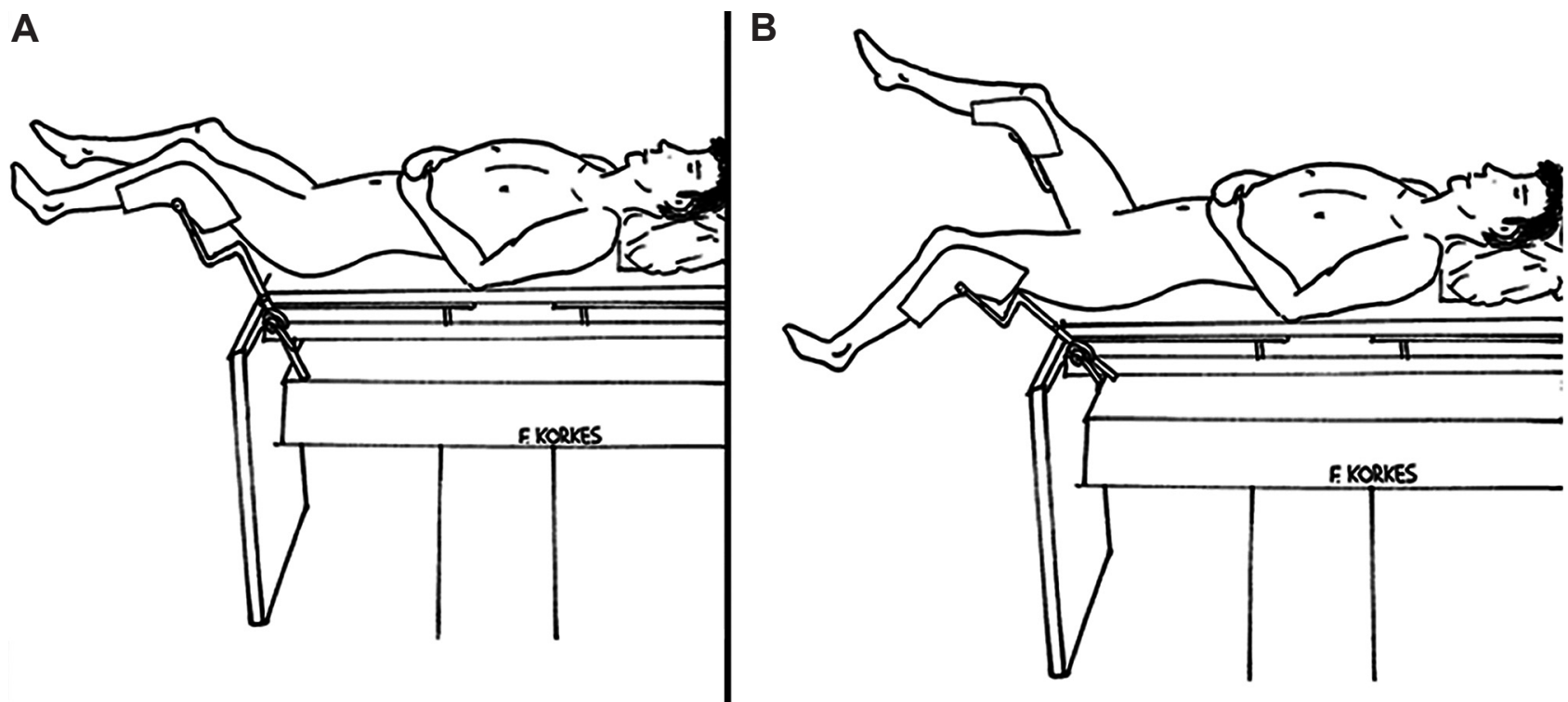

Figure 1 - Patient position during left ureteroscopy: A) Dorsal lithotomy position. B) Dorsal lithotomy with extended leg.

\section{MATERIALS AND METHODS}

A total of 98 patients treated for ureteral calculi at a single institution from January 2004 to January 2008 were randomized to either DL or DLEL position during URS, and were prospectively followed. All patients were operated by second-yearresidents-in-training, under supervision of the same urologist (ACLN), always as first assistant (total of eight residents). The ureteroscope ( $7.5 \mathrm{~F}$ rigid ureteroscope, Karl Storz, Germany), fluoroscopy, video monitor, baskets and irrigation devices were the same for both groups. Balloon ureteral dilatation was performed in selected cases for technical difficulties, and ureteral assess was always obtained after passing two guide wires. Lithotripsy was performed with pneumatic lithotripter (Swiss Lithoclast, Electro Medical Systems, Switzerland) under general or regional anesthesia. A $6 \mathrm{~F}$ or $7 \mathrm{~F}$ ureteral stent was inserted at the end of the procedure according to surgeon's judgment.

Patients and stone characteristics and operative outcomes were evaluated. Patients included in the study had ureteral calculi to be treated surgically. Exclusion criteria included the presence of infection, inadequate follow-up or hip limitations.
Two patients were excluded from the study. Main outcomes to be assessed included operative time, fluoroscopy time, intra-operative complications, postoperative complications, stone free rate, use of ureteral stents and length of hospital stay. Primary end-point was to leave the patient stone free with minimal morbidity, in a short period of time and with low radiation exposition. Statistical analysis was performed using the Statistical Package for Social Sciences software (SPSS 13.0 for Mac OS X, SPSS, Inc., Chicago, IL. USA). Student's-t test-was used to compare means and chi-square to compare categorical outcome variables. Statistical significance was determined at $p$ value less than 0.05 . All patients or parents/tutors signed an informed consent form, and the institutional review board approved the present study.

\section{RESULTS}

Of the 98 patients included in the study, 55 (56.1\%) were men and $43(43.9 \%)$ women with a mean age of $42.6 \pm 16.8$ years (range 9 - 84 years). Forty-eight patients underwent URS in DL position and 50 in DLEL position. Patients' age, mean stone 
size and location were similar between both groups (Table-1).

Operative outcomes for both groups are shown in Table-2. Operative time was longer for the DL vs. DLEL group (81.0 vs. 62.0 minutes, $\mathrm{p}=0.045$, Figure-2). Mean fluoroscopy use, complications and success rates were similar between both groups (Table-2). If men vs. women were compared in both groups, operative time was 95.2 vs. 64.5 minutes $(\mathrm{p}=$ $0.036)$ for DL and 63.9 vs. 59.5 minutes $(p=0.709)$ for DLEL. If DL men vs. DLEL men were compared, there was also a significant difference $(p=0.023)$, which did not occur between DL women vs. DLEL women $(p=0.668)$.

The intra-operative complication rate was $3.1 \%$, similar between both groups $(\mathrm{p}=0.371)$, with medical vs. surgical complications accounting for 1.0 vs. $2.1 \%$. Complications included one case of bronchospasm requiring tracheal intubation and 2 cases that required open conversion (one for ureteral damage while treating a large proximal stone in the DL group and one in DLEL group due to failure to access a large proximal stone). Minor complications occurred in $13.3 \%$ of the patients and included minor mucosal damage $(9.2 \%)$, equipment malfunction $(3.1 \%)$ and failure to place the ureteral stent $(1.0 \%)$.

\section{COMMENTS}

Intracorporeal lithotripsy technology has made it possible to successfully access and treat virtually any stone within the upper urinary tract $(1,8)$. Operative outcomes have been associated with several factors, such as stone size, stone location, energy source for lithotripsy, balloon dilatation, duration of stone disease, surgeon's experience, etc. (1,9-13). Most of these factors are inherent to patient's condi-

Table 1 - Characteristics and perioperative data in patients submitted to ureteroscopy in dorsal lithotomy (DL) position and in dorsal lithotomy with extended leg (DLEL) position.

\begin{tabular}{|c|c|c|c|c|}
\hline & $\begin{array}{l}\text { DL Position } \\
(\mathrm{N}=48)\end{array}$ & $\begin{array}{l}\text { DLEL Position } \\
(\mathrm{N}=50)\end{array}$ & $\begin{array}{l}\text { Overall } \\
(\mathrm{N}=98)\end{array}$ & \\
\hline Characteristics & Mean \pm SD & Mean \pm SD & Mean \pm SD & $\mathrm{p}$ Value \\
\hline Age (years) & $43.0 \pm 14.7$ & $42.3 \pm 18.4$ & $42.6 \pm 16.8$ & 0.835 \\
\hline Stone size (mm) & $10.1 \pm 4.1$ & $9.7 \pm 5.2$ & $9.9 \pm 4.8$ & 0.674 \\
\hline Stone area $\left(\mathrm{mm}^{2}\right)$ & $72.6 \pm 45.7$ & $65.3 \pm 56.7$ & $68.5 \pm 52.0$ & 0.500 \\
\hline \multirow[t]{2}{*}{ Stone history (days) } & $177.9 \pm 249.3$ & $121.4 \pm 151.5$ & $148.5 \pm 204.8$ & 0.251 \\
\hline & $\%(\mathrm{~N})$ & $\%(N)$ & $\%(\mathrm{~N})$ & $\mathrm{p}$ Value \\
\hline Gender & & & & 0.161 \\
\hline Male & $56.2(27)$ & $57.1(28)$ & $56.1(55)$ & \\
\hline Female & $43.7(21)$ & $42.9(22)$ & $43.9(43)$ & \\
\hline Prior ureteral surgery & $18.7(9)$ & $14.0(7)$ & $16.3(16)$ & 0.184 \\
\hline Stone location & & & & 0.110 \\
\hline Proximal & $25.0(12)$ & $32.0(16)$ & $28.6(28)$ & \\
\hline Middle & $8.3(4)$ & $8.0(4)$ & $8.2(8)$ & \\
\hline Distal & $66.7(32)$ & $60.0(30)$ & $63.2(62)$ & \\
\hline Anesthesia & & & & 0.233 \\
\hline General & $6.2(3)$ & $10.0(5)$ & $8.2(8)$ & \\
\hline Regional & $93.7(45)$ & $90.0(45)$ & $91.8(90)$ & \\
\hline
\end{tabular}

$*=p<0.05 ; p$ value by Student's- $t$-test and chi-square test. 


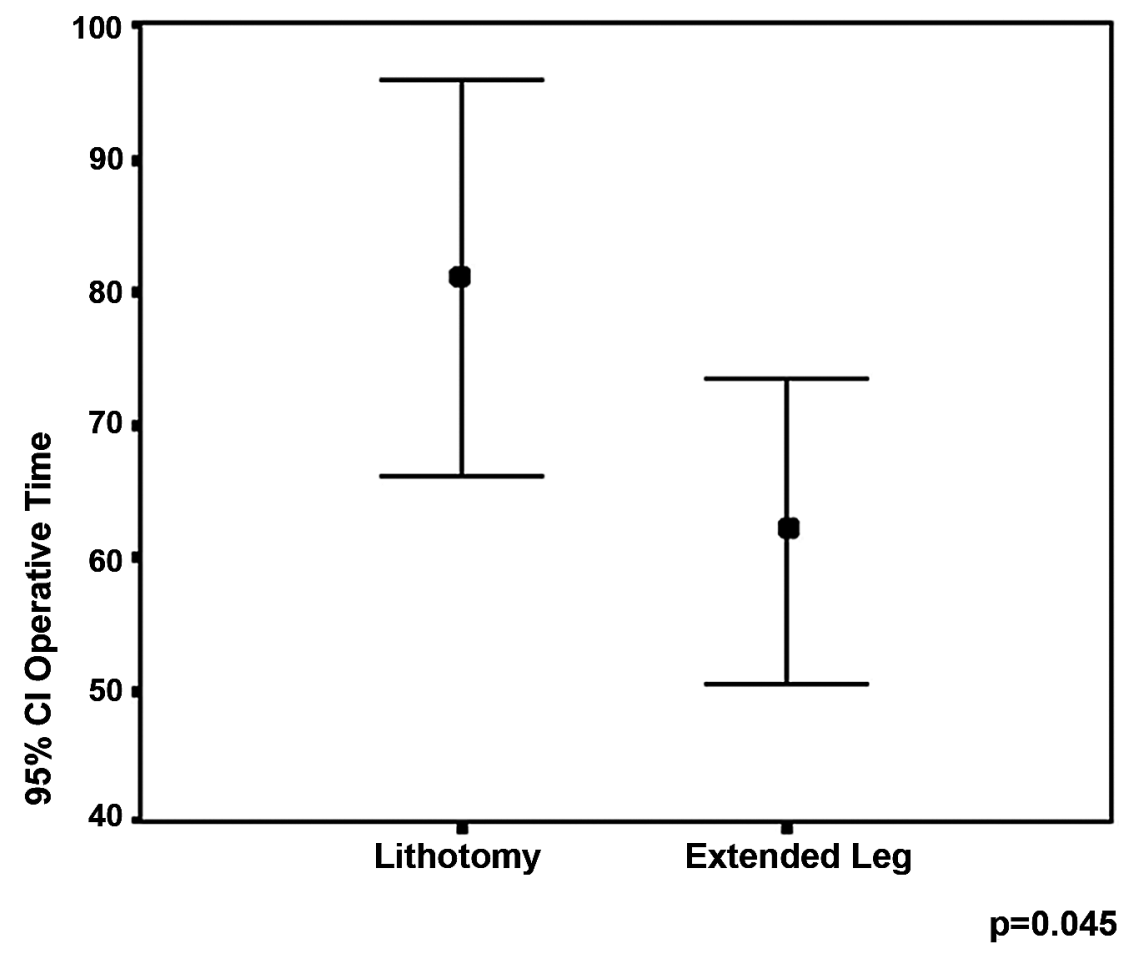

Figure 2-Operative time for dorsal lithotomy and dorsal lithotomy with extended leg.

tion or devices available at each center, and therefore cannot be changed. However, leg position is a simple factor that directly affects ureteral access and kinking and can easily be changed (7).
Different leg positions have been used during URS procedures. The position of the patient with the same side leg lower and medially positioned and with the other leg higher and more

Table 2 - Intraoperative characteristics according to dorsal lithotomy $(D L)$ position and to dorsal lithotomy with extended leg (DLEL) position.

\begin{tabular}{lcccc}
\hline & $\begin{array}{c}\text { DL Position } \\
(\mathrm{N}=48)\end{array}$ & $\begin{array}{c}\text { DLEL Position } \\
(\mathrm{N}=50)\end{array}$ & $\begin{array}{c}\text { Overall } \\
(\mathrm{N}=98)\end{array}$ & p Value \\
\hline Operative time (min.) & $81.0 \pm 47.3$ & $62.0 \pm 41.9$ & $70.2 \pm 45.1$ & $0.045^{*}$ \\
Fluoroscopy time (sec.) & $93.0 \pm 100.1$ & $80.7 \pm 82.6$ & $85.2 \pm 89.0$ & 0.591 \\
Ureteral dilatation & $2.1(1)$ & $2.0(1)$ & $2.0(2)$ & 0.505 \\
Intraoperative complications & $4.2(2)$ & $1.8(1)$ & $3.1(3)$ & 0.371 \\
Minor complications & $6.2(3)$ & $12.0(6)$ & $9.2(9)$ & 0.174 \\
Stone free & $85.4(41)$ & $90.0(45)$ & $87.7(86)$ & 0.192 \\
Ureteral stent & $84.0(42)$ & $92.0(46)$ & $89.8(88)$ & 0.202 \\
Length of stay (days) & $1.2 \pm 0.6$ & $1.5 \pm 0.9$ & $1.3 \pm 0.8$ & 0.104 \\
\hline
\end{tabular}

$*=p<0.05 ; p$ value by Student's- $t$-test and chi-square test. 
laterally positioned has the theoretical advantage of straightening the ureteral angle. Angus et al. have demonstrated in a radiographic study that the ureteral angle at the iliac vessels level straightens according to patient position, even though it does not interfere with the intramural portion of the ureter (7). However, other factors might also interfere such as the angle between the urethra/bladder neck and the ureteral orifice. It is noteworthy that the role of patient's position in URS outcomes has never, to our knowledge, been previously evaluated, and clinical studies are necessary to validate this experimental study. In fact, several studies that evaluate URS outcomes do not in fact mention which position patients were placed during procedures $(1,10,14)$.

Our study has some important findings. First, we have observed longer operative time when patients were in DL vs. DLEL position. Different authors have used different leg positions during URS (3-6), and according to our study, this detail directly affects the operative time. This observation might reflect an increased difficulty both to access the ureter and also that kinking in the ureter produces to stone fragmentation and removal, subsequently taking a longer time to access the ureter. Therefore, the theoretical support for the DLEL position might be correct. Since this observation, our group has adopted the DLEL as the standard position for URS. DLEL might not only straighten the ureter to be assessed, but also with the flexed leg, the surgeon and the assistant have a better working space.

Second, this difference was even more important when operating men, resulting in a significant decrease in operative time with DLEL position $(\mathrm{p}=0.02)$. For men, the extended leg might bring an additional benefit of straightening and aligning the urethra, which did not occur in women $(\mathrm{p}=$ 0.668 ).

Third, complication and success rates were similar for DL vs. DLEL groups, and both positions are feasible. Although surgery might be easier and faster when patients are positioned in DLEL, if for any reason the patient is positioned in DL, surgical outcomes are expected to be the same. If there are limitations regarding cystoscopy table positioning, URS can still be performed safely.
Our study has some limitations. First, this was not a blinded study, as the surgeon was aware of leg position. Nevertheless, we believe that this bias does not seem to affect surgical procedures. Further studies evaluating the length of time spent in each stage of surgery (bladder access, ureteral access, lithotripsy, ureteral stenting) as well as subjective impression of the level of difficulty according to patient position could produce additional information. Moreover, other important factors such as stone composition were not evaluated in the present study. However, this limitation is the same as in a clinical setting when this information cannot be obtained preoperatively. Moreover, as previously stated, stone composition is another factor that cannot be modified preoperatively, differently from leg position.

Complication and ureteral stenting rates were also slightly higher than in larger series. Possible reasons for these findings include the facts that these patients were operated by residents-in-training and as this population of patients have a great difficulty in fixing an appointment with the urologist, as we primarily treat large (mean size $9.9 \mathrm{~mm}$ ) and chronic (mean history time of 148 days) ureteral calculi. In this subset of patients, more complications are expected (15), and ureteral stenting can be beneficial (16). One case required open conversion due to ureteral avulsion while treating a large proximal stone, a rare complication of this procedure (this was the only event in our series of more than 900 ureteroscopies performed); the other patient had a $12 \mathrm{~mm}$ proximal stone that could not be reached with the ureteroscope. As we do not have a flexible ureteroscope or a flexible nephroscope, our option was to convert to an open surgery and remove the stone, with an unremarkable postoperative evolution.

In conclusion, patient position during URS directly affects operative time. Even though success and complication rates are not related to position, placing the patient in dorsal lithotomy position with an extended leg seems to make the surgery easier and faster, specially when operating males.

\section{CONFLICT OF INTEREST}

None declared. 


\section{REFERENCES}

1. Preminger GM, Tiselius HG, Assimos DG, Alken P, Buck C, Gallucci M, et al.: 2007 guideline for the management of ureteral calculi. J Urol. 2007; 178: 2418-34.

2. Rofeim O, Yohannes P, Badlani GH: Does laparoscopic ureterolithotomy replace shock-wave lithotripsy or ureteroscopy for ureteral stones? Curr Opin Urol. 2001; 11: 287-91.

3. Ziaee SA, Halimiasl P, Aminsharifi A, Shafi H, Beigi FM, Basiri A: Management of 10-15-mm proximal ureteral stones: ureteroscopy or extracorporeal shockwave lithotripsy? Urology. 2008; 71: 28-31.

4. Watterson JD, Girvan AR, Beiko DT, Nott L, Wollin TA, Razvi H, et al.: Ureteroscopy and holmium:YAG laser lithotripsy: an emerging definitive management strategy for symptomatic ureteral calculi in pregnancy. Urology. 2002; 60: 383-7.

5. Lopes Neto AC, Gava MM, Mattos MHE, Borreli M, Wroclawski ER: Treatment of ureteral calculi by ureteroscopy: experience of 100 cases at the Faculdade de Medicina do ABC (FMABC - Medical School). Einstein. 2004; 2: 28-32.

6. Su LM, Sosa ES: Ureteroscopy and Retrograde Ureteral Access. In: Walsh PC (ed.), Campbell's Urology. Philadelphia, Saunders, 2002; pp. 3314.

7. Angus DG, Webb DR: Influence of hip flexion on the course of the ureter. Ureteroscopic implications. Eur Urol. 1988; 14: 287-90.

8. Preminger GM, Tiselius HG, Assimos DG, Alken P, Buck AC, Gallucci M, et al.: 2007 Guideline for the management of ureteral calculi. Eur Urol. 2007; 52: 1610-31.
9. Al-Awadi K, Kehinde EO, Al-Hunayan A, Al-Khayat A: Iatrogenic ureteric injuries: incidence, aetiological factors and the effect of early management on subsequent outcome. Int Urol Nephrol. 2005; 37: 235-41.

10. Leijte JA, Oddens JR, Lock TM: Holmium laser lithotripsy for ureteral calculi: predictive factors for complications and success. J Endourol. 2008; 22: 257-60.

11. Korkes F, Gomes SA, Heilberg IP: Diagnosis and treatment of ureteral calculi. J Bras Nefrol. 2009; 31: 55-61.

12. Natalin R, Xavier K, Okeke Z and Gupta M: Impact of obesity on ureteroscopic laser lithotripsy of urinary tract calculi. Int Braz J Urol. 35: 36-41; discussion 41-2, 2009.

13. Fuganti PE, Pires SR, Branco RO and Porto JL: Ballistic ureteroscopic lithotripsy in prepubertal patients: a feasible option for ureteral stones. Int Braz J Urol. 32: 322-7; discussion 327-9, 2006.

14. Mugiya S, Ozono S, Nagata M, Takayama T, Nagae H: Retrograde endoscopic management of ureteral stones more than $2 \mathrm{~cm}$ in size. Urology. 2006; 67: 1164-8; discussion 1168.

15. Brito AH, Mitre AI, Srougi M: Ureteroscopic pneumatic lithotripsy of impacted ureteral calculi. Int Braz J Urol. 2006; 32: 295-9.

15. Hao P, Li W, Song C, Yan J, Song B, Li L: Clinical evaluation of double-pigtail stent in patients with upper urinary tract diseases: report of 2685 cases. J Endourol. 2008; 22: 65-70.
Accepted after revision:

June 8, 2009

\section{Correspondence address:}

Dr. Fernando Korkes

Rua Pirapora, 167

São Paulo, SP, 04008-060, Brazil

Fax: + $55113884-2233$ 


\section{EDITORIAL COMMENT}

Ureteroscopy is the first line treatment for ureteral lithiasis except in some cases. Perez-Castro et al. described the technique of lowering the contralateral limbs to facilitate the expansion and advancement of the ureteroscope (1). Currently, most of the groups perform the procedure by telesurgery in the classic lithotomy position, although the position has been modified to improve access and to facilitate the extraction and removal of stone fragments. In this article, the authors analyzed the results of ureteroscopy in two positions; classic lithotomy and lithotomy with homolateral leg extended, referenced by other authors (2), and they have observed significant differences in surgical time in men (not in women), without significant differences in the other parameters analyzed. Endourology techniques have been performed in different positions to improve the access to the ureter. Angus et al. reported that increasing the degree of the lithotomy position improves the access to the iliac ureter (3). On the other hand, Bercowsky et al. studied infundibulo-pelvic angle of lower calyx and they found that the lower pole infundibulo-pelvic angle broadens when the patient lies in a prone 20-degree head down position (4). Herrell et al. used flank position in ureteroscopy to treat complex calyceal lithiasis because the extraction is facilitated due to gravity (5).
The results published in this article by Korkes et al. show that lithotomy with homolateral extended leg position is a valid approach for ureteral lithiasis and it provides an alternative to classic lithotomy position. However, it is important to gain more experience in the use of this position and we must consider studying other parameters that could influence the results and surgical time, like the size of prostate gland that in some occasions can render the access and the mobility of the semi-rigid ureteroscope difficult.

\section{REFERENCES}

1. Pérez-Castro E, Martínez Piñeiro JA: La ureterorrenoscopia transuretral: un actual proceder urológico. Arch Esp Urol. 1980; 33: 445-60.

2. Arrabal Martín M, Ocete Martín C, Jiménez Pacheco A, Miján Ortiz JL, Pareja Vilches M, Zuluaga Gómez A: Metodología y límites de la ureteroscopia ambulatoria Arch Esp Urol. 2006; 59: 261-72.

3. Angus DG, Webb DR: Influence of hip flexion on the course of the ureter. Ureteroscopic implications. Eur Urol. 1988; 14: 287-90.

4. Bercowsky E, Shalhav AL, Elbahnasy AM, Owens E, Clayman RV: The effect of patient position on intrarenal anatomy. J Endourol. 1999; 13: 257-60.

5. Herrell SD, Buchanan MG: Flank position ureterorenoscopy: new positional approach to aid in retrograde caliceal stone treatment. J Endourol. 2002; 16: 15-8.

\author{
Dr. Miguel A. Arrabal-Polo \\ Section of Urology \\ San Cecilio University Hospital \\ Granada, Spain \\ E-mail:arrabalp@ono.com
}

\section{EDITORIAL COMMENT}

Surgeons have historically been particular about patients' position during surgery. This is important for access, minimizing pressure points and prevention of deep vein thrombosis during extended operation time. Early experience with the rigid ure- teroscopy has identified two regions of the ureter that can be difficult to negotiate, the first at the vesicoureteric junction and the second anterior to the iliac bifurcation. During initial days of ureteroscopy use of large size (13F or plus) ureteroscopes mandated that 
all possible efforts should be made to ease passage of the scope through narrow parts of the ureter. However, there is dearth of scientific literature on the efficacy of such maneuvers. Korkes and colleagues (1) have looked into the impact of the outcome on one position (dorsal lithotomy with leg extended) over traditional dorsal lithotomy. Although they did not observe any significant advantage of one procedure over the other, they have noted some advantage in operative time using extended leg position. More than two decades ago, Angus and Webb (2) noted that the lower ureter possesses two curves, an upper curve at the iliac bifurcation that straightens with increasing degrees of lithotomy and a lower vesical curve in the pelvis, which is unaltered by patient position. Dagnone et al. (3) applied lower-abdominal pressure to see if it facilitates semi rigid-ureteroscopy to access to the upper ureter for safe laser lithotripsy using a 7.5F scope. They observed that lower-abdominal pressure could be helpful to negotiate passage of the endoscope over the iliac vessels or to place the laser fiber on stones.
In conclusion, this is a small basic study looking at an innocuous modification that may have beneficial impact on the ease of accessing two difficult points in the distal and middle ureter. In a larger cohort of patients preferably at a multi institutional setting, future investigators may be able to note a significant difference.

\section{REFERENCES}

1. Korkes F, Neto ACL, Mattos MH, Pompeo AC, Wroclawski ER: Patient position and semi-rigid ureteroscopy outcomes. Int Braz J Urol. 2009 [In Press]

2. Angus DG, Webb DR: Influence of hip flexion on the course of the ureter. Ureteroscopic implications. Eur Urol. 1988; 14: 287-90.

3. Dagnone AJ, Blew BD, Pace KT, Honey RJ: Semirigid ureteroscopy of the proximal ureter can be aided by external lower-abdominal pressure. J Endourol. 2005; 19: 342-7.

Dr. M. Hammad Ather Associate Professor Director Urology Residency Program Aga Khan University Karachi, Pakistan E-mail:hammad.ather@aku.edu

\section{EDITORIAL COMMENT}

Ureterorenoscopy (URS), extracorporeal shock wave lithotripsy (SWL) and percutaneous nephrolithotomy (PCNL) are the main modalities for modern stone treatment. While all of these procedures have shown to be as effective minimally invasive treatment for various stone situations, there are always demands to further excel their performance. One of the most common ways to improve this situation is by the help of technological advancement. The development of digital optics, scope design and auxiliary instruments has greatly improved the performance of URS and PCNL, in particular flexible instruments (1). Similarly, there have also been improvements in tech- nology of SWL that can bring the performance back to the standard set by HM3 (2). However, all these new developments will inevitably increase the capital cost of medical treatment, which will be particular important in the current economic turmoil. As a result, the real impact of these technical advancements may not be as great as could be expected, especially for the developing countries.

However, there is also another approach to improve the performance by modifying the working condition or treatment protocols of the existing equipment. As well demonstrated by this article, the simple modification of the leg position will help to 
improve the performance of semi-rigid URS (3). This simple and easy approach required no extra-cost for equipment, but can shorten the operating time, in particular for male patients by $30 \%$. There are also other approaches that have been reported to improve the performance of URS, such as instillation of lidocaine jelly proximal to the stone to minimize stone flush back and improve stone free rate (4). Similarly, modifications of treatment protocols for SWL, such as modification of shockwave delivery rate (5) and application of gel on the treatment head (6), has also shown to be effective in the improvement of treatment outcomes. These kinds of non-costly procedures for improvement of treatment performance will definitely benefit more patients worldwide than the simple pursuit of high technological equipment.

One of the pitfalls of this study, as already discussed by the authors, is the "non-blinded" nature of the study. As the surgeon performed the operation will know the positioning of the legs, therefore any subjective preference or bias to one of the positions may lead to bias in part of the results, such as the operating time. However, this kind of bias will be intrinsic to most of the surgical studies and is difficult, if not impossible, to completely eliminate. Therefore, one should be aware of this bias during the interpretation of results. Nevertheless, the authors have convincingly demonstrated the superiority of the dorsal lithotomy position with same side leg slightly extended (DLEL) over dorsal lithotomy position (DL) during URS. This approach should be encouraged in our daily practice.

\section{REFERENCES}

1. Canes D, Desai MM: New technology in the treatment of nephrolithiasis. Curr Opin Urol. 2008; 18: 235-40.

2. Nomikos MS, Sowter SJ, Tolley DA: Outcomes using a fourth-generation lithotripter: a new benchmark for comparison? BJU Int. 2007; 100: 1356-60.

3. Korkes F, Neto ACL, Mattos MH, Pompeo AC, Wroclawski ER: Patient position and semi-rigid ureteroscopy outcomes. Int Braz J Urol. 2009 [In Press]

4. Zehri AA, Ather MH, Siddiqui KM, Sulaiman MN: A randomized clinical trial of lidocaine jelly for prevention of inadvertent retrograde stone migration during pneumatic lithotripsy of ureteral stone. J Urol. 2008; 180: 966-8.

5. Semins MJ, Trock BJ, Matlaga BR: The effect of shock wave rate on the outcome of shock wave lithotripsy: a meta-analysis. J Urol. 2008; 179: 194-7; discussion 197.

6. Neucks JS, Pishchalnikov YA, Zancanaro AJ, VonDerHaar JN, Williams JC Jr, McAteer JA: Improved acoustic coupling for shock wave lithotripsy. Urol Res. 2008; 36: 61-6.
Dr. Anthony NG Chi-fai Associate Professor Division of Urology Department of Surgery The Chinese University of Hong Kong E-mail:ngcf@surgery.cuhk.edu.hk 